\title{
Impact of topography on black carbon transport to the southern Tibetan Plateau during the pre-monsoon season and its climatic implication
}

Meixin Zhang et al.

Correspondence to: Chun Zhao (chunzhao@ustc.edu.cn)

The copyright of individual parts of the supplement might differ from the CC BY 4.0 License. 


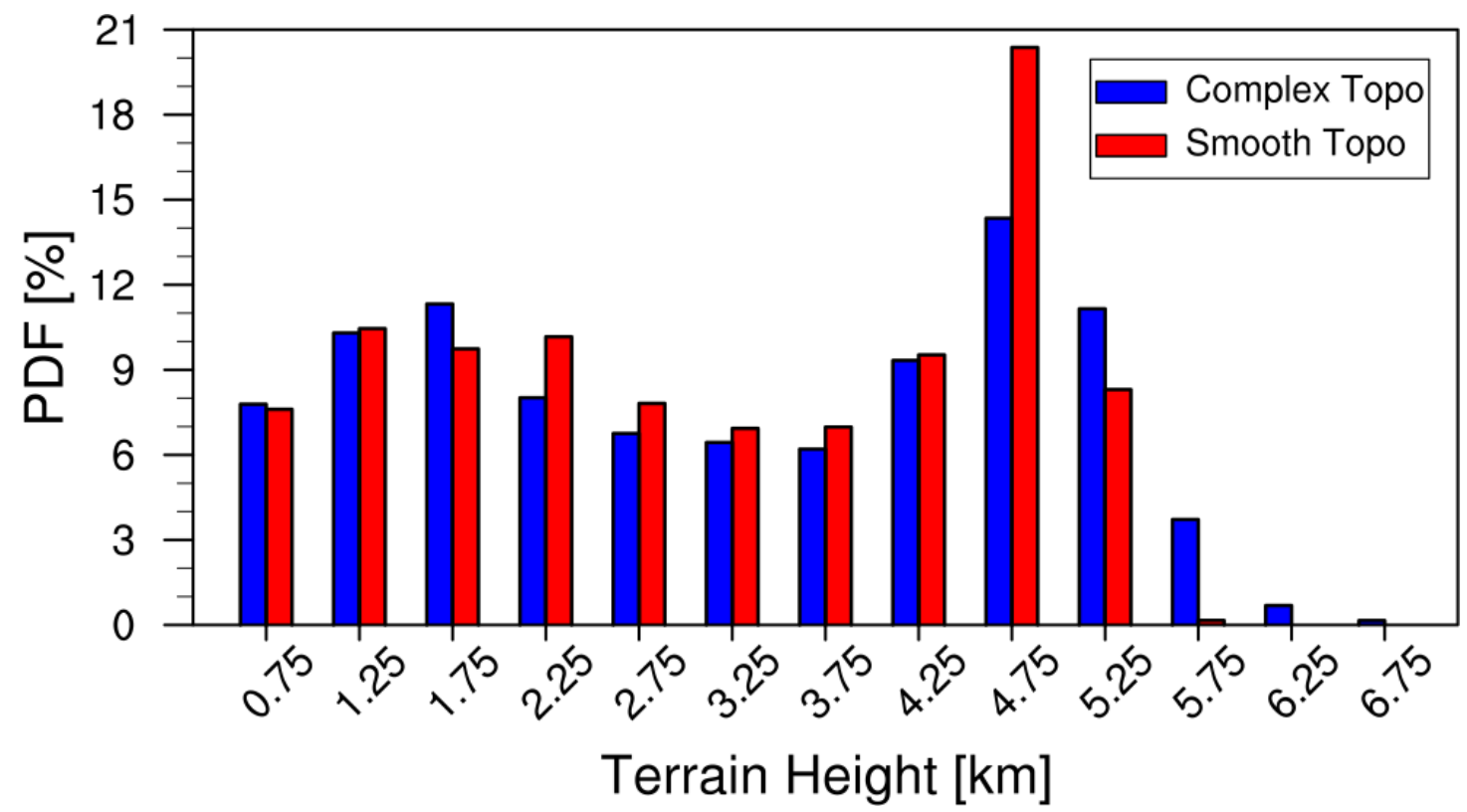

Figure S1. Probability distributions of terrain height over Himalayas from the dataset at $20 \mathrm{~km}$ (smooth topo) and $4 \mathrm{~km}$ (complex topo) shown in Fig. 3. 

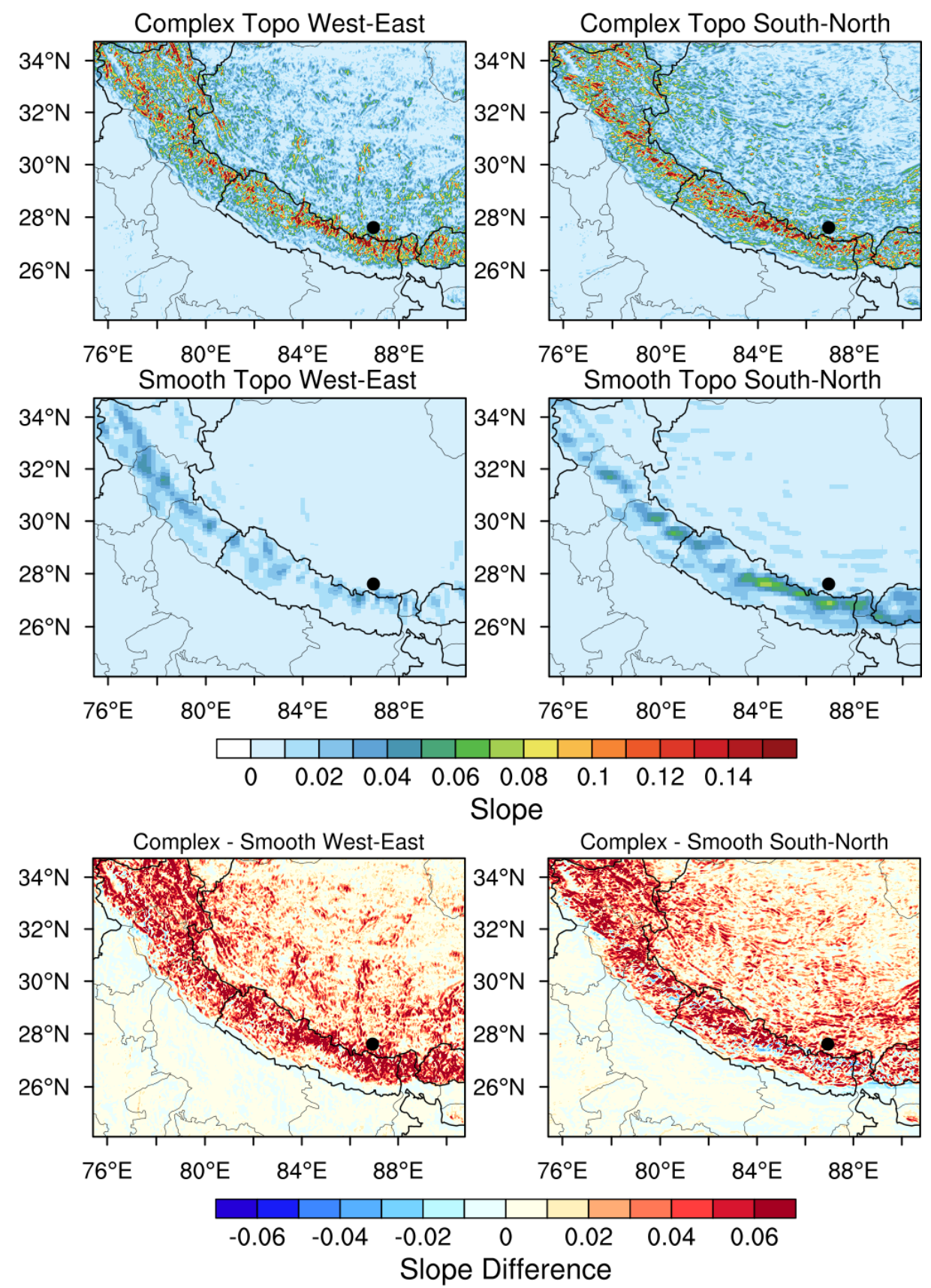

Figure S2. The slopes between the neighboring grids in our $4 \mathrm{~km}$ simulation domain with the complex and smooth topographies. The slopes are calculated in west-east and south-north direction by the formula: slope $=|(\mathrm{z} 1-\mathrm{z} 2) / \mathrm{dx}|$, where $\mathrm{z} 1$ and $\mathrm{z} 2$ denote the terrain heights (in $\mathrm{km}$ ) of the two neighboring grids and $\mathrm{dx}$ is $4 \mathrm{~km}$. 


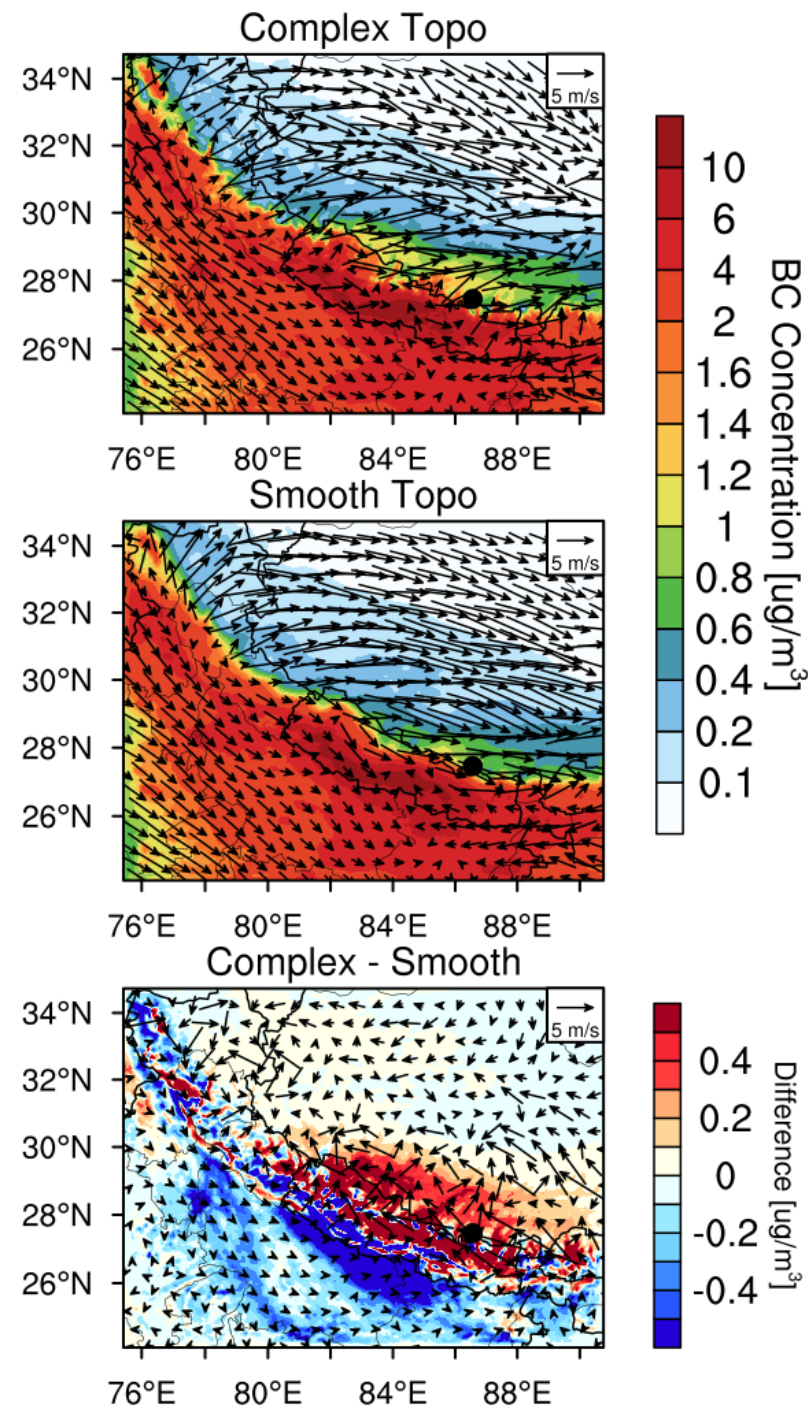

Figure S3. Spatial distributions of near-surface BC concentration and horizontal wind field within $500 \mathrm{~m}$ above the ground over the TP from the simulations with the complex and smooth topographies. The difference between the two is also shown. The results averaged within $2 \mathrm{~km}$ above the ground are consistent. 


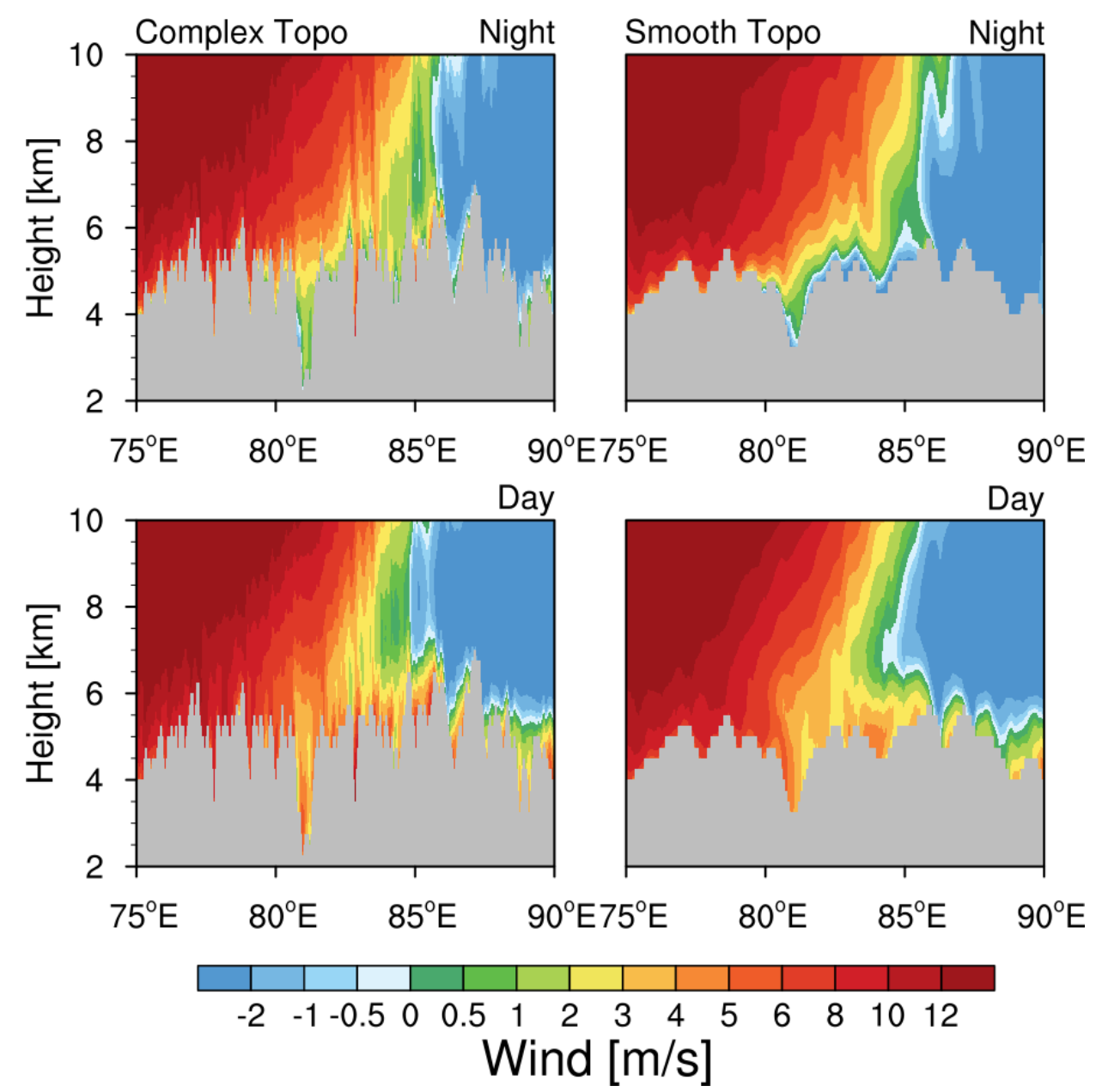

Figure S4. Cross section of horizontal wind along the black dashed cross line shown in Fig. 3. Positive values represent the wind direction towards the TP, while negative values represent the wind direction away from the TP. Nighttime is defined as 21:006:00 local time, and daytime is defined as 9:00-18:00 local time. 

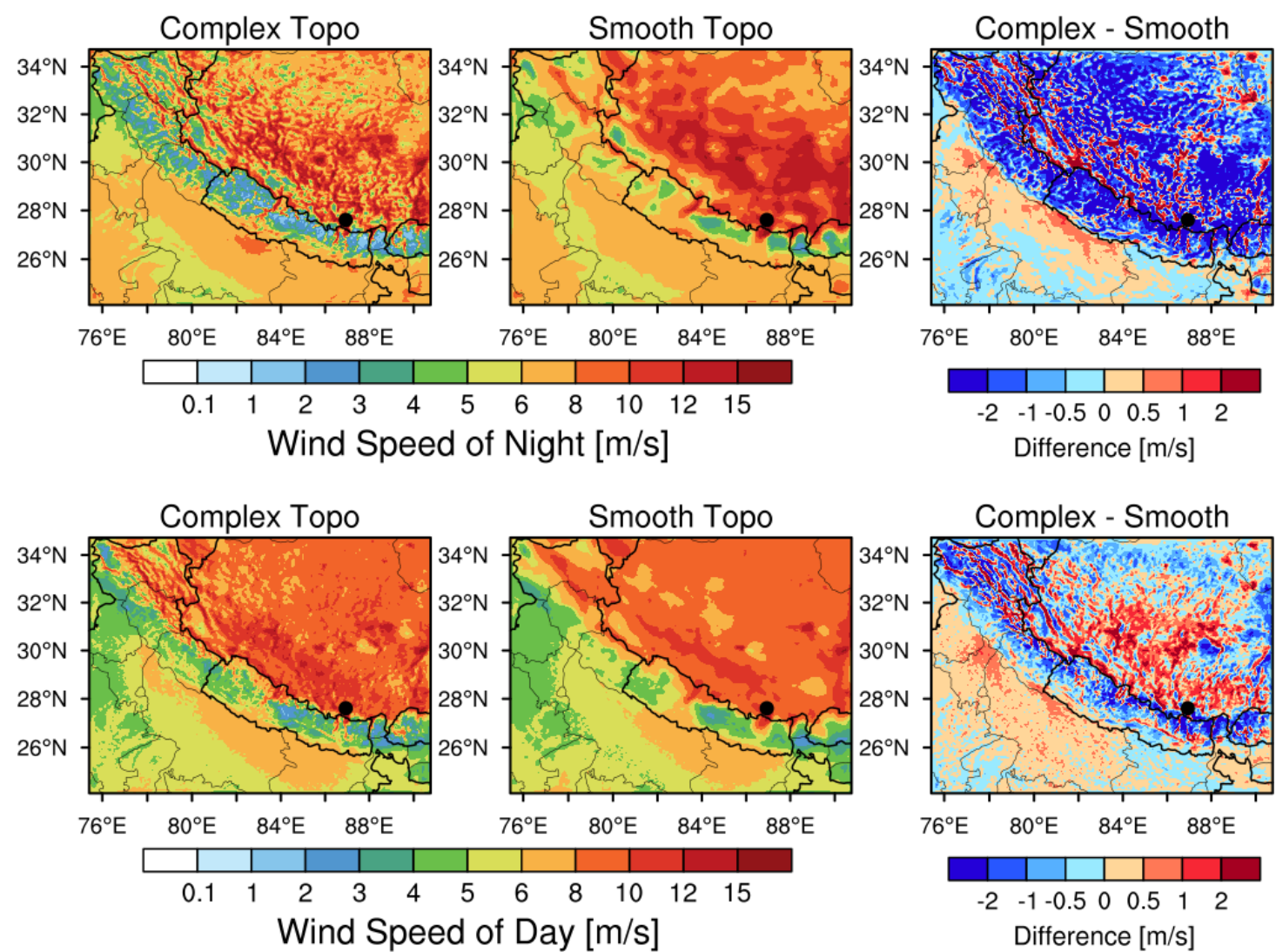

Figure S5. Spatial distributions of wind speed averaged within $500 \mathrm{~m}$ above the ground for day and night during 1-20 April 2016 from the simulations with the complex and smooth topographies. The difference between the two is also shown. Nighttime is defined as 21:00-6:00 local time, and daytime is defined as 9:00-18:00 local time. The results averaged within $2 \mathrm{~km}$ above the ground are consistent. 


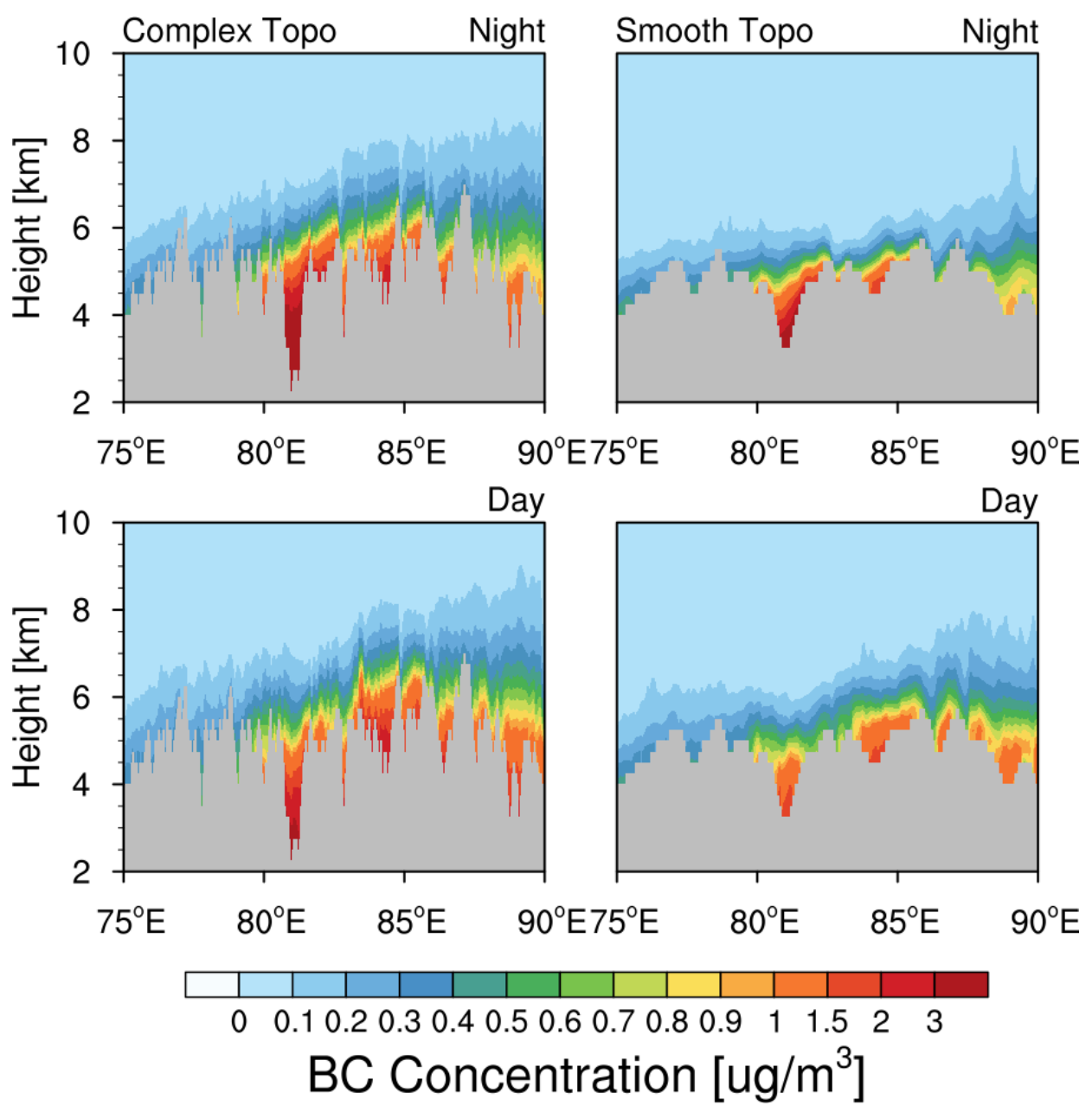

Figure S6. Cross section of $\mathrm{BC}$ concentration along the black dashed cross line shown in Fig. 3, nighttime is defined as 21:00-6:00 local time, and daytime is defined as 9:0018:00 local time. 

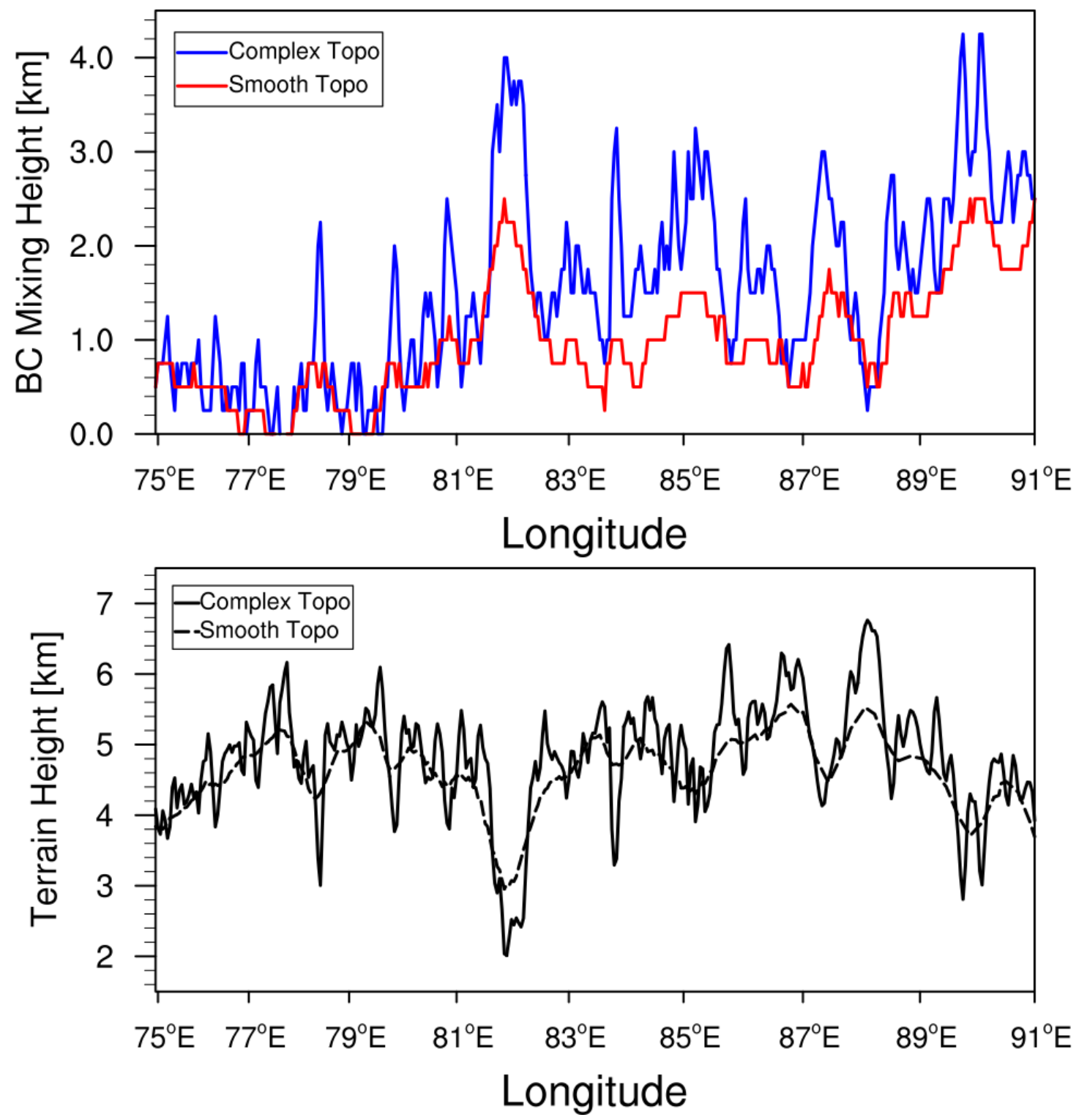

Figure S7. Longitudinal distribution of mixing height below which the BC mass concentration is larger than $0.3 \mathrm{ug} / \mathrm{m}^{3}$ along the cross section in Fig. 3 from the simulations with the complex and smooth topographies. The black lines represent the terrain heights with different topographies. 

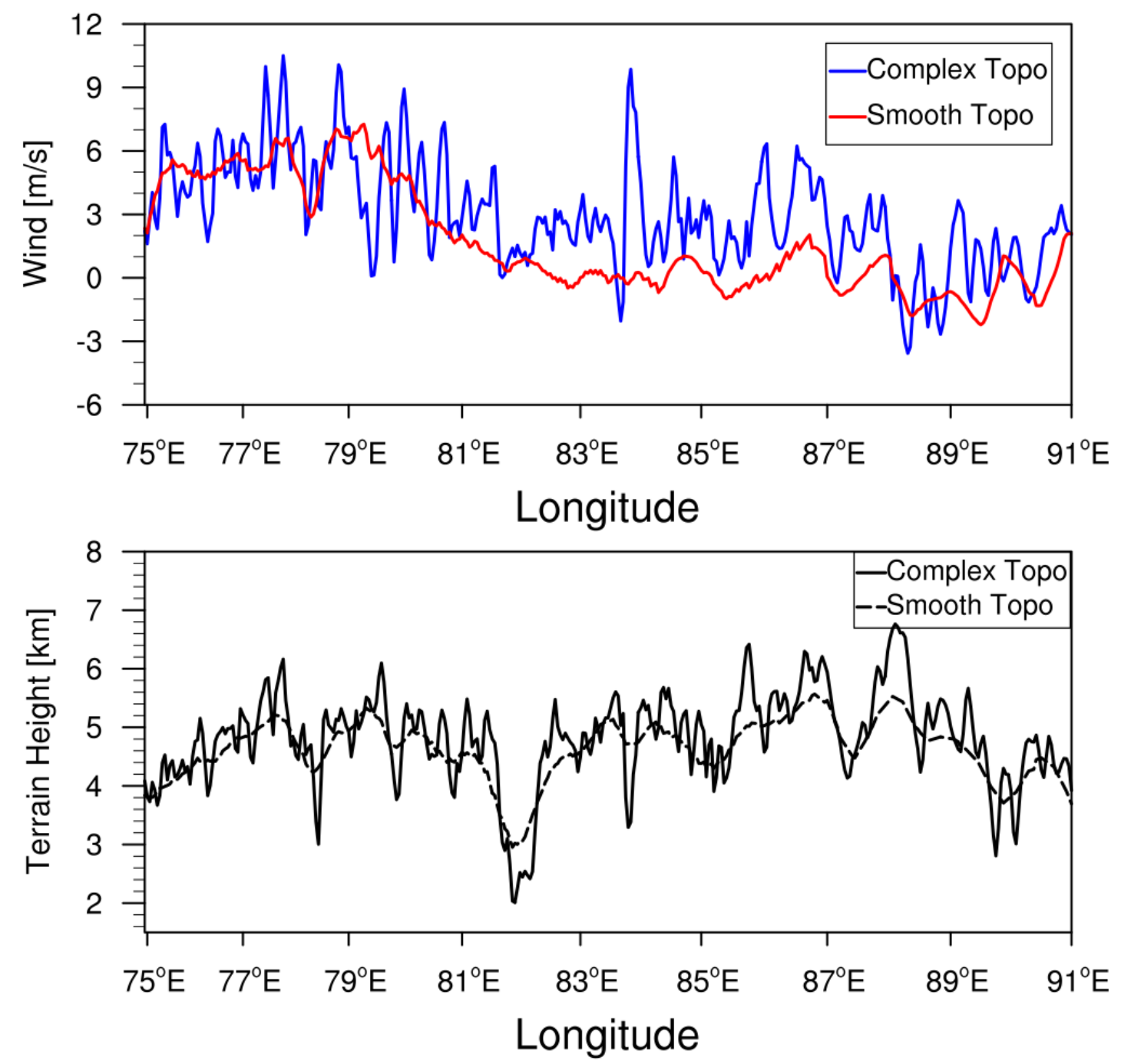

Figure S8a. Longitudinal distribution of near-surface wind averaged within $500 \mathrm{~m}$ above the ground along the cross section in Fig. 3 from the simulations with the complex and smooth topographies. The black lines represent the terrain heights with different topographies. Similar as Fig. 12, positive values represent the wind direction towards the TP, while negative values represent the wind direction away from the TP. The results averaged within $2 \mathrm{~km}$ above the ground are consistent. 

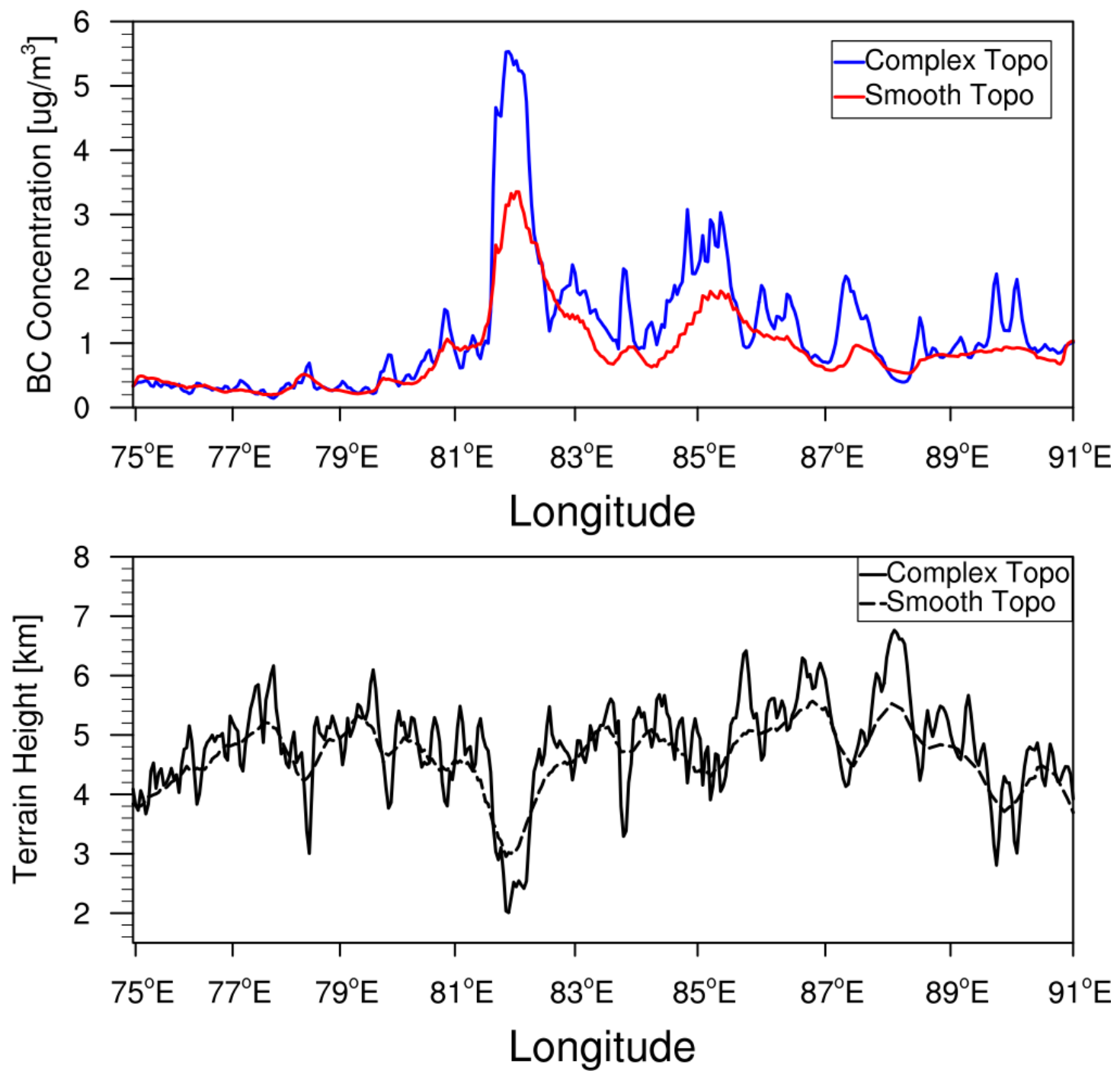

Figure S8b. Longitudinal distribution of near-surface BC mass concentration averaged within $500 \mathrm{~m}$ above the ground along the cross section in Fig. 3 from the simulations with the complex and smooth topographies. The black lines represent the terrain heights with different topographies. The results averaged within $2 \mathrm{~km}$ above the ground are consistent. 


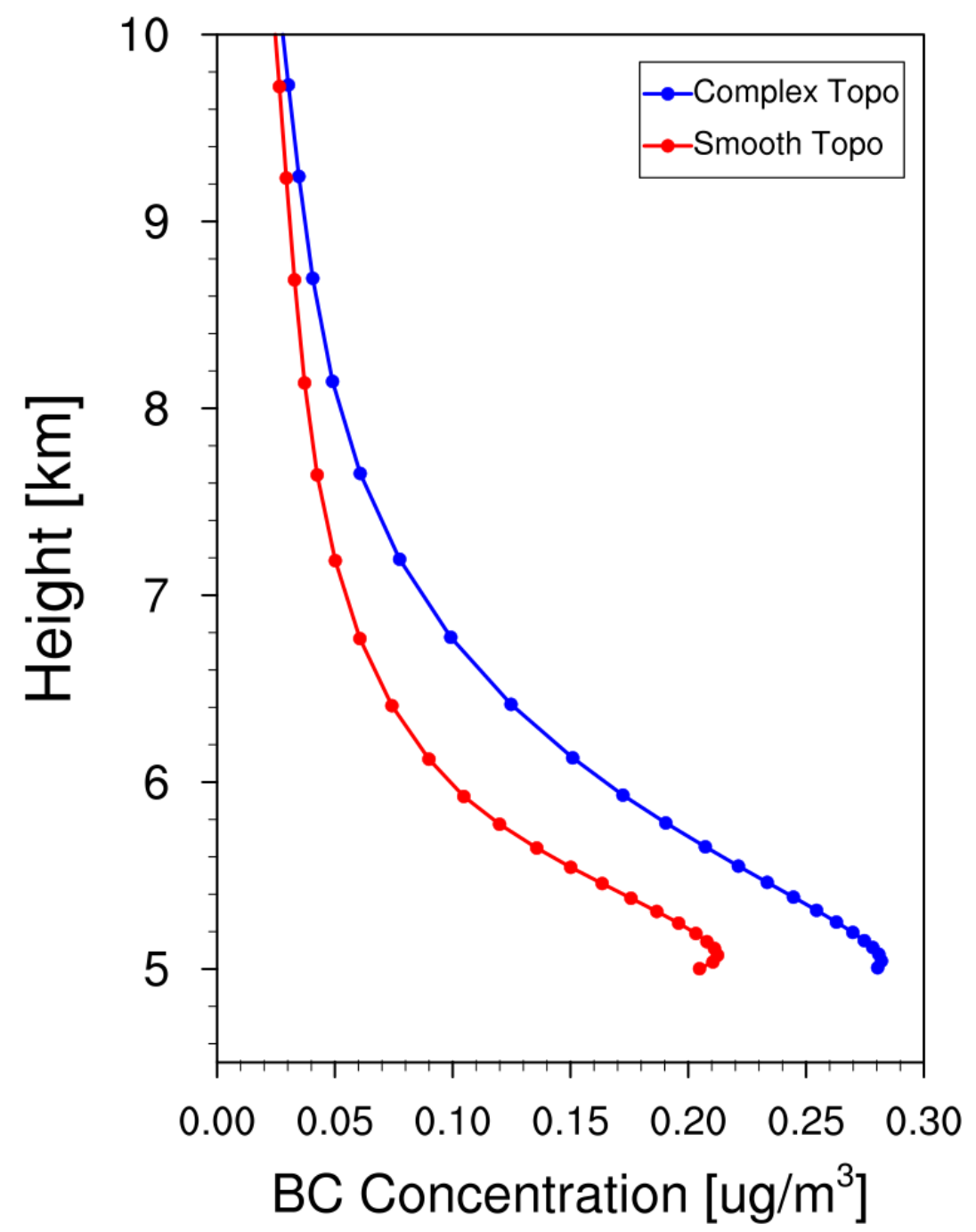

Figure S9. Vertical profiles of BC concentration averaged over the TP (with elevation > $4 \mathrm{~km}$ ) from the simulations with the complex and smooth topographies during 1-20 April 2016. 


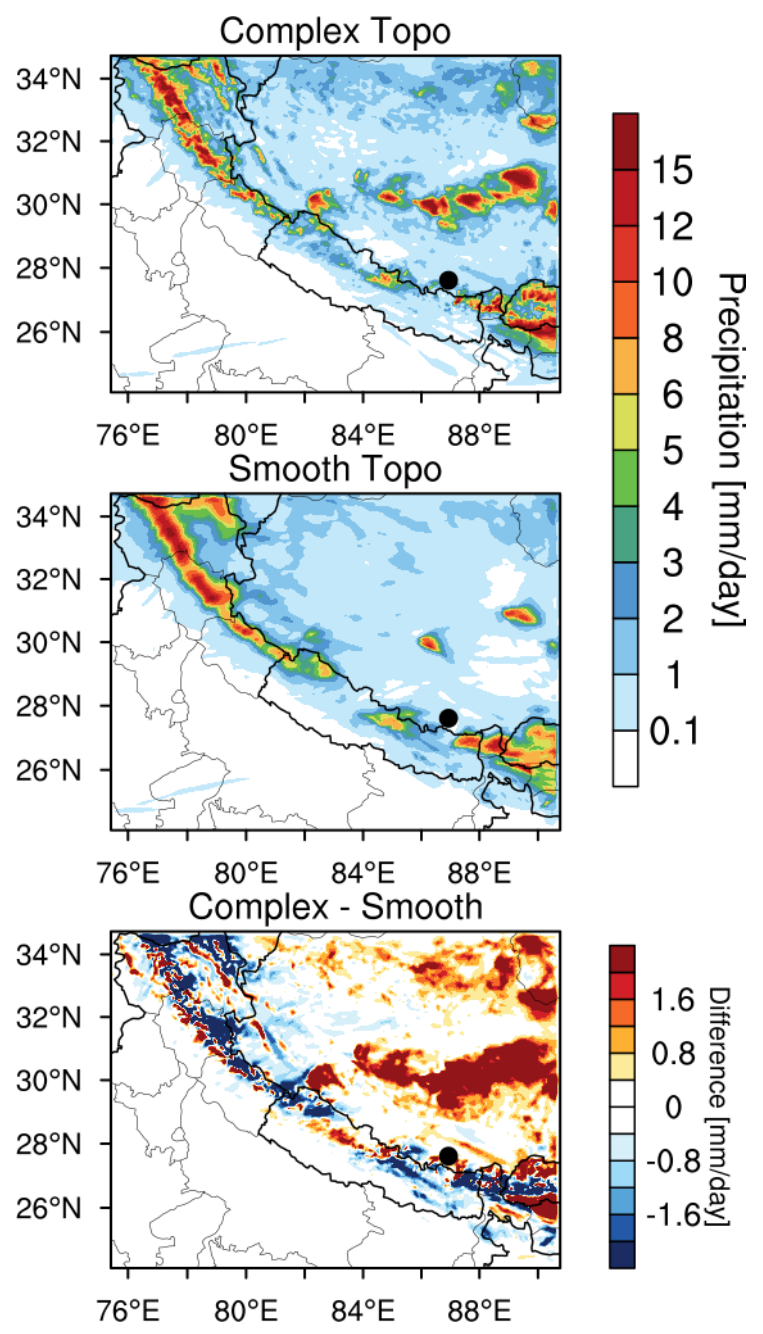

Figure S10. Spatial distributions of precipitation averaged for 1-20 April 2016 from the simulations with the complex and smooth topographies. The difference between the two is also shown. 


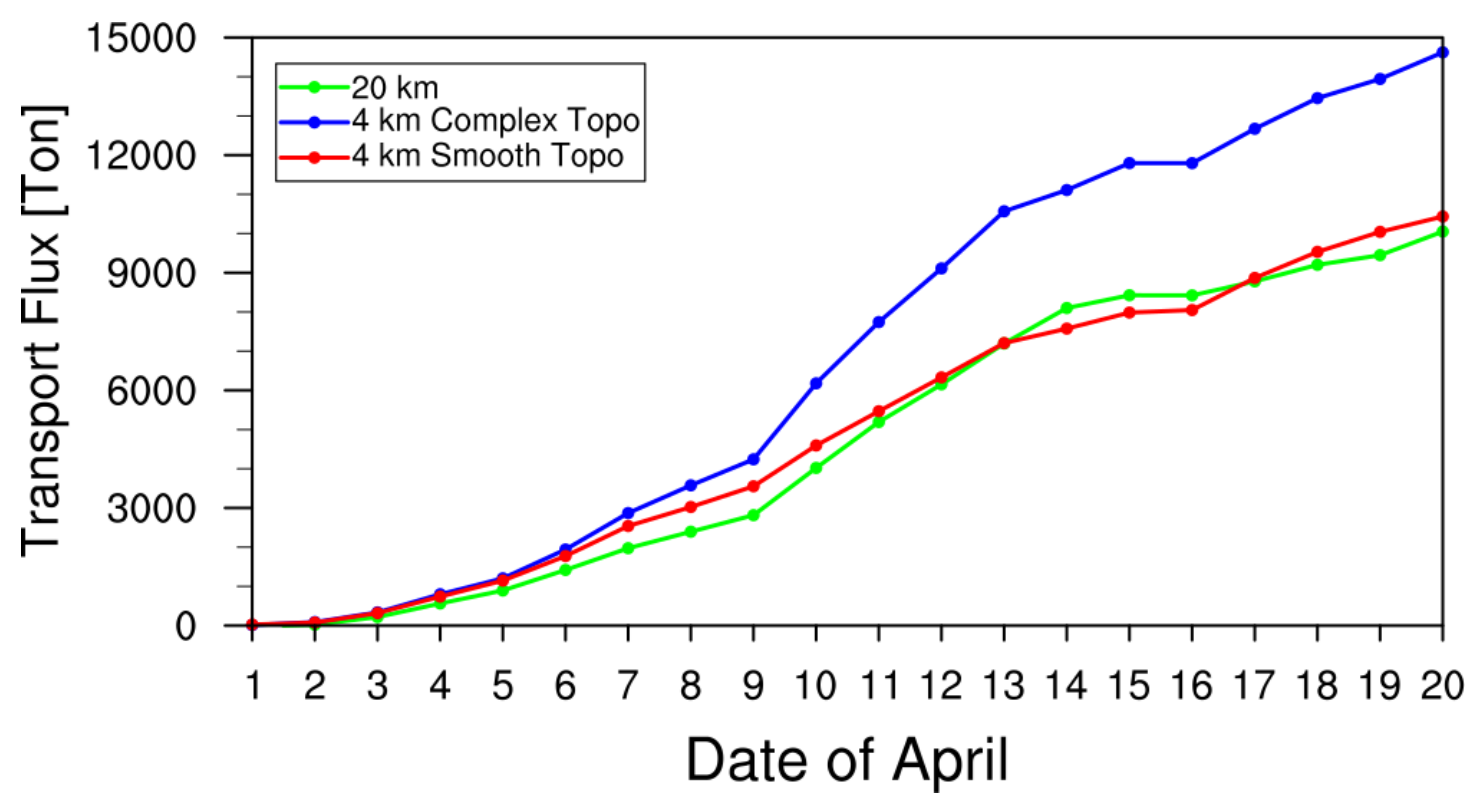

Figure S11. Accumulated integrated total transport flux of BC across the Himalayas estimated from the simulations at $20 \mathrm{~km}$ and $4 \mathrm{~km}$ resolutions during 1-20 April 2016. The sensitivity experiment at $4 \mathrm{~km}$ resolution but with the smooth $20 \mathrm{~km}$ topography is also shown. 


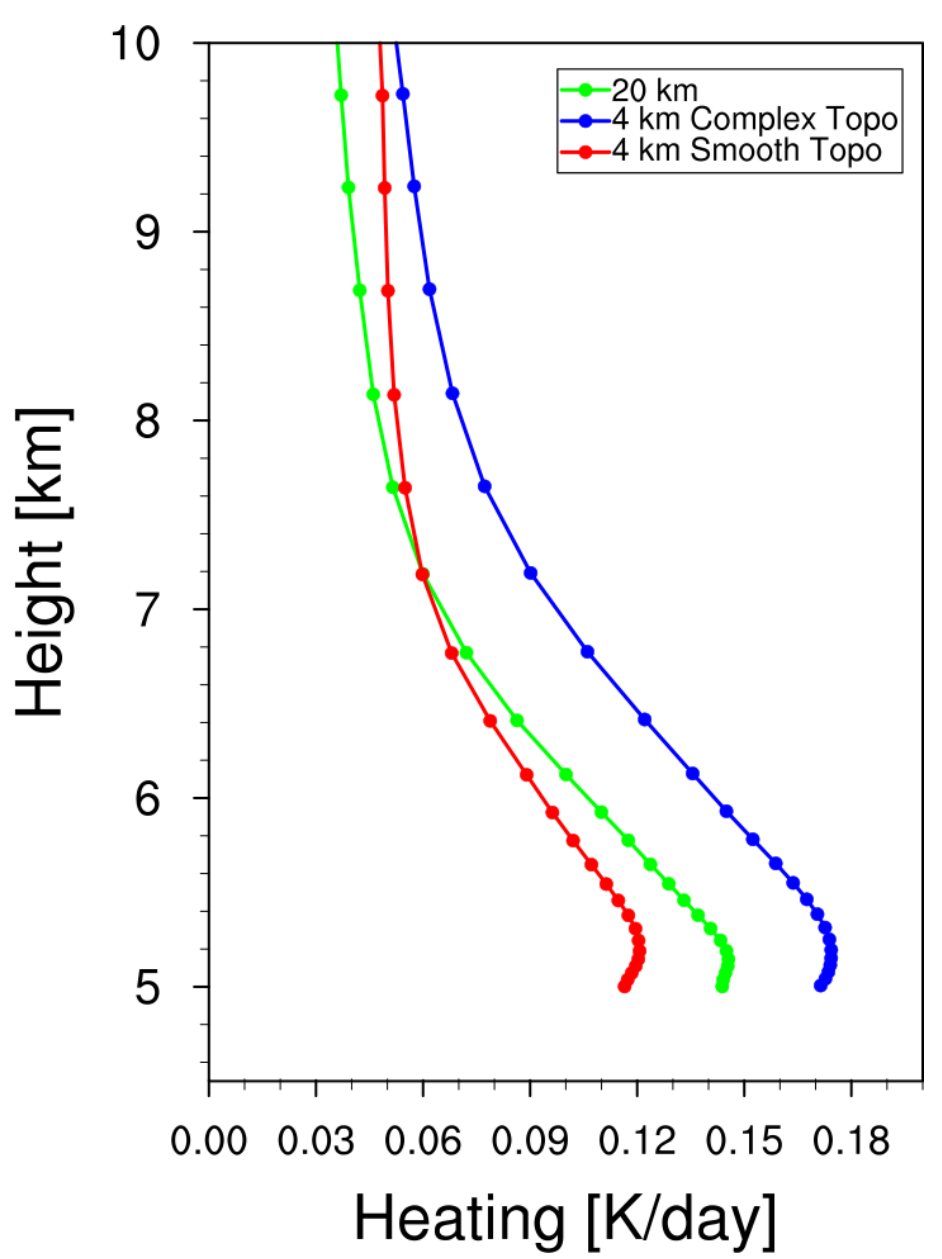

Figure S12. Vertical profiles of $B C$ induced radiative heating rate in the atmosphere averaged over the TP (with elevation $>4 \mathrm{~km}$ ) within the inner domain shown in Fig.1 from the simulations at $20 \mathrm{~km}$ and $4 \mathrm{~km}$ resolutions during 1-20 April 2016. The sensitivity experiment at $4 \mathrm{~km}$ resolution but with the smooth $20 \mathrm{~km}$ topography is also shown. 


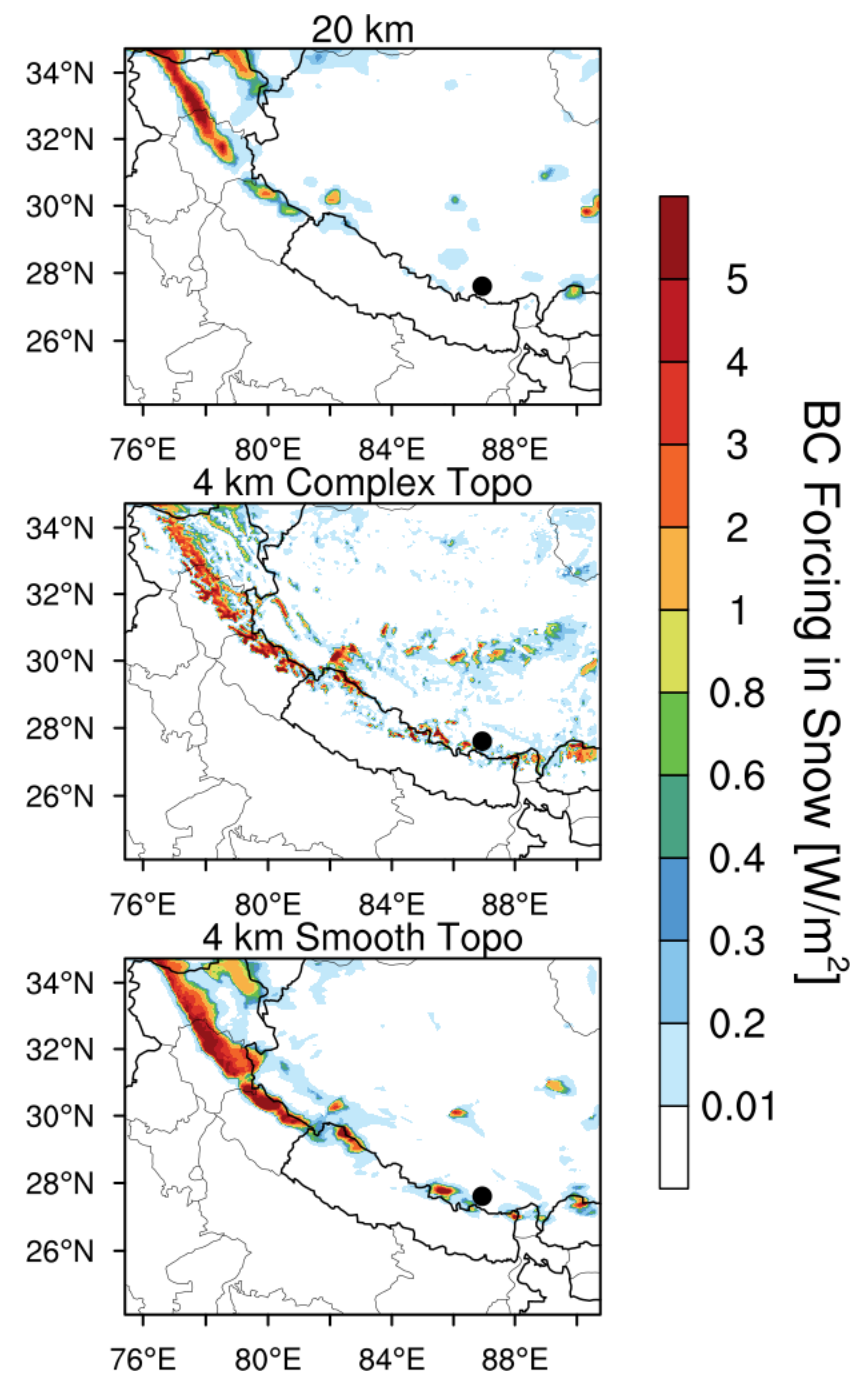

Figure S13. Spatial distributions of BC radiative forcing in the surface snow averaged for 1-20 April 2016 from the simulations at $20 \mathrm{~km}$ and $4 \mathrm{~km}$ resolutions. The sensitivity experiment at $4 \mathrm{~km}$ resolution but with the smooth $20 \mathrm{~km}$ topography is also shown. 